\title{
Atuação, monitoramento e análise de processos erosivos no âmbito de parques eólicos: estudo de caso nas regiões litorânea e agreste do Nordeste brasileiro
}

\author{
Acting, monitoring and analysis of erosive processes in the context of wind farms: a case \\ study in the coastal and Agreste regions of brazilian northeast
}

\author{
SANTOS $^{1}$, W. A. A. dos; SOUZA ${ }^{2}$, H. C. de \\ welson_geo@yahoo.com.br
}

\begin{abstract}
Resumo
Este artigo tece considerações acerca das atividades desenvolvidas no âmbito da execução de um plano de controle e monitoramento de processos erosivos em parques eólicos localizados no agreste potiguar e no litoral cearense. O objetivo primordial vincula-se a execução de operações que visem excluir e/ou mitigar ações causadas pela atuação negativa promovida pelos processos erosivos no interior dos parques eólicos e, recuperar o equilíbrio ambiental que tenha sido comprometido. A metodologia de campo utiliza-se, baseia-se fundamentalmente em vistorias de campo com intuito de registrar os processos erosivos e, proceder a observância de técnicas que promovam a prevenção e/ou correção dos processos erosivos como instrumento de preservação e conservação ambiental. Nas atividades executadas observa-se que as obras civis relacionadas a implantação de parques eólicos devem observar atentamente a premissas ambientais com vistas a atenuar os impactos ambientais decorrentes das atividades de implantação dos parques eólicos para que o mínimo de impactos ambientais venham a ser gerados.
\end{abstract}

Palavras-chave: processos erosivos, parques eólicos, Agreste potiguar.

\begin{abstract}
This article presents considerations about the activities developed in the framework of the implementation of a management plan and monitoring of erosion in wind farms located in Rio Grande do Norte and Ceará wild. The primary objective is linked to the implementation of operations aimed at excluding and/or mitigating actions caused by negative actions promoted by erosion inside of wind farms and restore the environmental balance that has been committed. The methodology used in field, it is mainly based on field surveys in order to record the erosive processes and undertake compliance techniques that promote the prevention and/or correction of erosion as conservation tool and environmental conservation. The activities carried out it is observed that the civil works related to implementation of wind farms should carefully observe the environmental requirements in order to mitigate the environmental impacts of the implementation activities of the wind farms to the minimum environmental impact will be generated.
\end{abstract}

Keywords: erosive processes, wind farm, Agreste potiguar.

\section{INTRODUÇÃO}

A organização das sociedades civilizadas baseia-se nas medidas tomadas para controlar e conviver harmonicamente com a natureza. Enquanto isso não se realizar totalmente, torna-se impossível lidar com a terra, em caráter estável. Quaisquer que sejam as razões é um fato indubitável que a erosão é um dos problemas mais prementes da humanidade: ela já arruinou milhões de hectares de terras antes cultiváveis e já reduziu muitos outros a uma situação definitivamente pauperizada. CASSETI (1996) ressalta que a relação do homem com o meio contém em si duplo aspecto, ou seja, é relação ecológica e relação histórica social, tem-se que a 
questão ambiental encontra-se fundamentada na relação de propriedade das forças produtivas, determinada pela relação homem-homem. Em face de tal complexidade, RODRIGUES (1998, p. 14), apud SILVA et. al., 2008, destaca que os problemas ecológicos parecem, à primeira vista, referir-se apenas às relações homem/natureza e não às relações dos homens entre si. É preciso, assim, ter cuidado para não ocultar a existência e as contradições de classes sociais para compreender a problemática ambiental em sua complexidade, pois os problemas ambientais dizem respeito a formas como o homem em sociedade se apropria da natureza.

A partir desse contexto, pondera-se que as atividades relativas às energias renováveis na atualidade vêm se configurando como um cenário irreversível e se desnuda com vistas à complementação de uma nova matriz energética, e vem sendo desenvolvida em função do atendimento as novas demandas sociais e econômicas do Brasil.

No aspecto de evolução das atividades no segmento eólico, as alterações ambientais trazem em seu bojo modificações em compartimentos ambientais que devem ser alvos de especial atenção, dentre eles, destacam-se os solos que respondem pela base de toda a existência do setor eólico. A erosão, entendida como um processo natural de degradação, decomposição, transporte e deposição de materiais de rochas e solos, vêm agindo sob a superfície do planeta desde o seu princípio, sendo os processos erosivos classificados através de seus agentes atuantes, podendo ser de origem eólica, hídrica ou até mesmo glacial. Quanto às formas de desgaste do solo, os processos erosivos podem ser subdivididos em superficial e subterrâneo. Por conservação do solo, dever-se-á entender a preservação e o desenvolvimento, de modo a proporcionar o maior bem para o maior número e pelo maior período de tempo, dos recursos naturais de caráter renovável, quais sejam, o próprio solo, as coberturas vegetais, as pastagens, a fauna silvestre e, a água.

Diante desse escopo, o artigo ora destacado apresenta uma série de resultados sobre o monitoramento, o controle e as principais formas de processos erosivos atuantes em dois complexos eólicos, localizados em áreas ambientalmente distintas, na região Nordeste do Brasil, que serão apresentadas a seguir.

\section{Caracterização e localização geográficas da área de estudo}

O primeiro complexo eólico estudado está localizado entre os municípios de João Câmara e Parazinho, região Agreste do Estado do Rio Grande do Norte, distante 75 km da capital, Natal. Já o segundo complexo eólico ora descrito, está inserido na região litorânea do município de Trairí, distante 124 km, aproximadamente, da capital do Estado do Ceará, Fortaleza (Figura 01). 
A primeira área, correspondente ao complexo eólico do Agreste do Rio Grande do Norte, está assentada sobre uma base litoestatigráfica correspondente à Formação Jandaíra, a Formação Açu, o Grupo Barreiras, o Complexo João Câmara e a Suíte Intrusiva Itaporanga. Quanto às feições geomorfológicas, a área é representada pela Depressão Sertaneja, com formas tabulares e convexas, e por Tabuleiros, com superfície pediplanada e formas tabulares. Outros dois fatores preponderantes, no que se refere à formação de processos erosivos, bem como o entendimento de sua atuação e monitoramento, versa sobre as condições climáticas e pluviométricas regionais. A área estudada configura-se como uma zona de transição entre o Litoral e o Agreste Norte-riograndense apresentando, portanto, duas classificações climáticas: Clima Tropical Subsumido seco e o Semiárido.

Em se tratando da segunda área, encontra-se localizada no litoral Cearense, configurada pela grande dinâmica geoambiental, tendo com arcabouço geológico as seguintes unidades: Grupo Barreiras, Complexo Canindé do Ceará e Complexo granítico-migmatítico Tamboril-Santa Quitéria. Já no que concerne aos aspectos geomorfológicos, à área apresenta depósitos litorâneos do Quaternário, com a presença de campos dunares, planícies de deflação, restingas, eolianitos, dentre outras. No que tange as condições climáticas dessa área a região em questão é regida pelo clima Tropical Quente Semiárido Brando, com índices pluviométricos moderados.

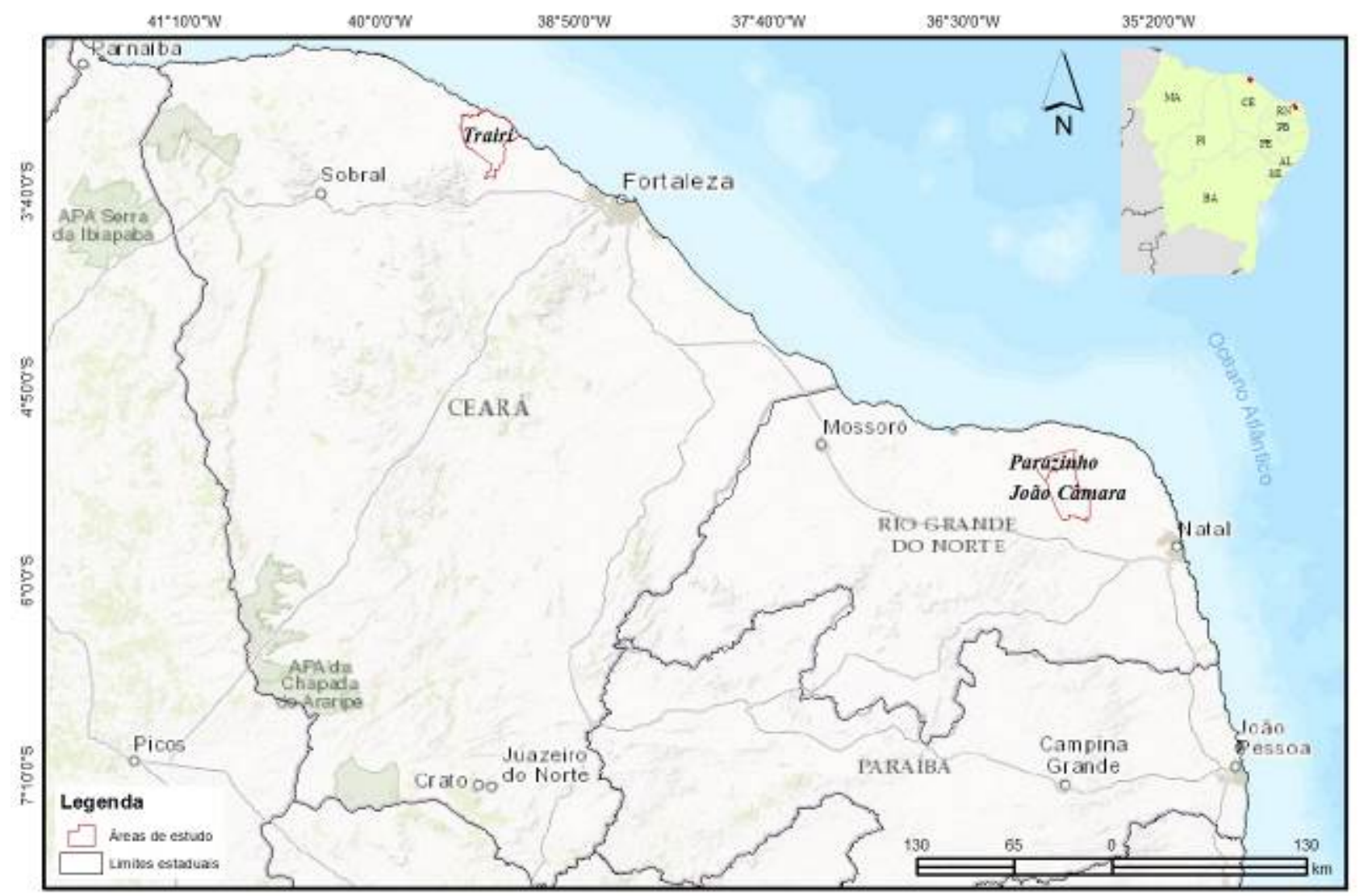


Figura 01. Localização das áreas de estudo no município nos municípios de João Câmara, Parazinho e Trairí, nos estados do Rio Grande do Norte e Ceará, respectivamente. Fonte. O autor.

\section{METODOLOGIA}

Para o desenvolvimento e implementação de Programas de Controle e Monitoramento de Processos Erosivos em complexos eólicos, se adota comumente como metodologia o levantamento exploratório de campo com vistas a subsidiar a observação e análise das ocorrências de processos erosivos que afetem direta e/ou indiretamente as estruturas e vias de acesso que transpassam os parques eólicos, normalmente atribuído à sua área de influência direta. Dentre os locais adotados para as vistorias de campo destacam-se as áreas correspondente às vias de acessos internas destes, os cortes de taludes, as áreas do entorno das bases dos aerogeradores e quaisquer outros locais susceptíveis a ocorrência de processos erosivos.

Na metodologia aqui descrita, realizou-se a identificação de taludes com formação erosões laminares, sulcos, ravinas e voçorocas; avaliação dos corpos estradais já devidamente implantados; avaliação nas bases dos aerogeradores implantados; verificação das condições de funcionalidade dos sistemas de drenagem instalados; e observação de áreas susceptíveis a ocorrência de processos erosivos.

Em campo, foi efetivada a localização de processos erosivos a partir da observação visual no âmbito dos parques eólicos. Procedida tal observação, tomou-se o registro de coordenadas Universal Transversal Mercator (UTM) através de uso de receptor GNSS para cada ponto onde haja detecção de processo erosivo. Neste mesmo ponto foram obtidas fotografias com uso de máquina fotográfica, assim como a realização de medições internas e externas no processo atuante (comprimento, altura e profundidade) dos processos erosivos ocorrentes através de uso de trena circular portátil.

Diante das informações observadas e coletadas foi realizado o preenchimento da ficha de registro de campo, a qual assegura todas as informações inerentes ao monitoramento de processos erosivos, tais como: caracterização do processo erosivo ocorrente, relevo da área analisada, cobertura vegetal presente, textura sedimentar, elenco das causas e fatores principais ligadas ao processo erosivo, criticidade do processo erosivo e registro fotográfico. Com as informações devidamente obtidas e registradas, deu-se o início aos trabalhos de gabinete que consistiram na elaboração de mapas com a locação dos processos erosivos encontrados e, por fim na elaboração de 
Relatórios conclusivos que tratam das medidas mitigadoras e/ou de exclusão dos processos erosivos ocorrentes.

\section{RESULTADOS E DISCUSSÃO}

Segundo BERTONI (2005) para controlar a erosão, é preciso deter não só o escoamento da enxurrada (lixiviação) que transporta as partículas de solo como também, e principalmente, o efeito da dispersão dos agregados do solo, eliminando o desprendimento das partículas causadas pelas gotas de chuva.

Em se tratando da cobertura vegetal, a mesma age como mecanismo de defesa natural do terreno contra a erosão. O efeito da vegetação pode ser através de (a): proteção direta contra o impacto das gotas de chuva; dispersão da água, interceptando-a e evaporando-a antes que atinja o solo; decomposição das raízes das plantas que, formando canalículos no solo, aumentam a infiltração da água; melhoramento da estrutura do solo pela adição de matéria orgânica, aumentando assim sua capacidade de retenção de água; e, diminuição da velocidade de escoamento da enxurrada pelo aumento do atrito na superfície.

Conforme GUERRA (2007), a perda de solo por erosão depende do potencial da chuva para erodir, definido pela erosividade da chuva; e da suscetibilidade do solo à erosão, definida pela erodibilidade do solo.

Todas as técnicas utilizadas para aumentar a resistência do solo ou diminuir as forças do processo erosivo denominam-se práticas conservacionistas. Estas podem ser divididas em vegetativas, edáficas e mecânicas. Dentre as práticas adotadas no segmento do controle e monitoramento de processos erosivos a prática vegetativa é mais concebível e exequível para sanar os problemas oriundos da ocorrência de processos erosivos (White, 2009).

O que se analisa em campo em sua amplitude é que há uma grande variabilidade quanto aos relevos encontrados que compreende desde relevos planos a fortemente ondulados, assim como há grande diferenciação pedológica com a ocorrência de solos coesos e incoesos e, de incipiente a forte movimentação de partículas sedimentares. Quando da ocorrência de incipiente transporte sedimentar evidencia-se, principalmente, pelo preponderante e importante papel exercido pela cobertura vegetal que fixa a estrutura do solo não permitindo maiores mobilizações sedimentares e, consequentemente, deixando as parcelas de solo devidamente protegidas contra a ocorrência de processos erosivos de origem eólica e/ou pluvial, especificamente, mais atuante esta última forma de erosão. No tocante a solos desnudos, a ocorrência de processos erosivos se faz presente devido à 
exposição do solo aos agentes exógenos e a ausência de cobertura vegetal, a qual conforme anteriormente exposto confere a proteção necessária para que o processo erosivo não surja.

Nas áreas destacadas nesta pesquisa verifica-se que dentre os fatores que nos levam a caracterizar processos erosivos, são: ausência de dispositivos de drenagem de águas pluviais, pisoteio de gado, existência de taludes desnudos, alterações de ordem antropogênica, rompimento ou insuficiência de sistema de drenagem de águas pluviais e ausência de cobertura vegetal. Dentre as atividades desenvolvidas no âmbito do plano de controle e monitoramento de processos erosivos se faz importante a investigação quanto a susceptibilidade erosiva do solo, a qual é observada em função da existência ou não de estoques de cobertura vegetal ou quaisquer outras formas de proteção do solo que conferem a este uma situação de proteção/conservação estrutural/textural.

Diante do exposto, as análises correspondentes aos dois complexos eólicos foram realizadas de maneira a evidenciar os processos erosivos, as formas de monitoramento e as medidas mitigadoras em cada complexo eólico estudado, em subitens destacados a seguir.

\section{Monitoramento e Processos erosivos do complexo eólico no Agreste Potiguar}

A área correspondente ao agreste Potiguar tem como principal agente intempérico a água, que acarreta em processos erosivos de origem pluvial. Associado a este fator natural, notou-se que a área do complexo eólico possui uma variação topográfica discreta, porém nos locais onde as cotas altimétricas passaram de 90 metros, o índice de erosão foi superior aos locais com relevo menos acidentado ou escarpado. Os principais resultados decorrentes da erosão verificados neste local foram a formação dos sulcos e dos ravinamentos associados ao forte escoamento laminar, advindo da precipitação e da diferença do gradiente topográfico (Figura 02). 

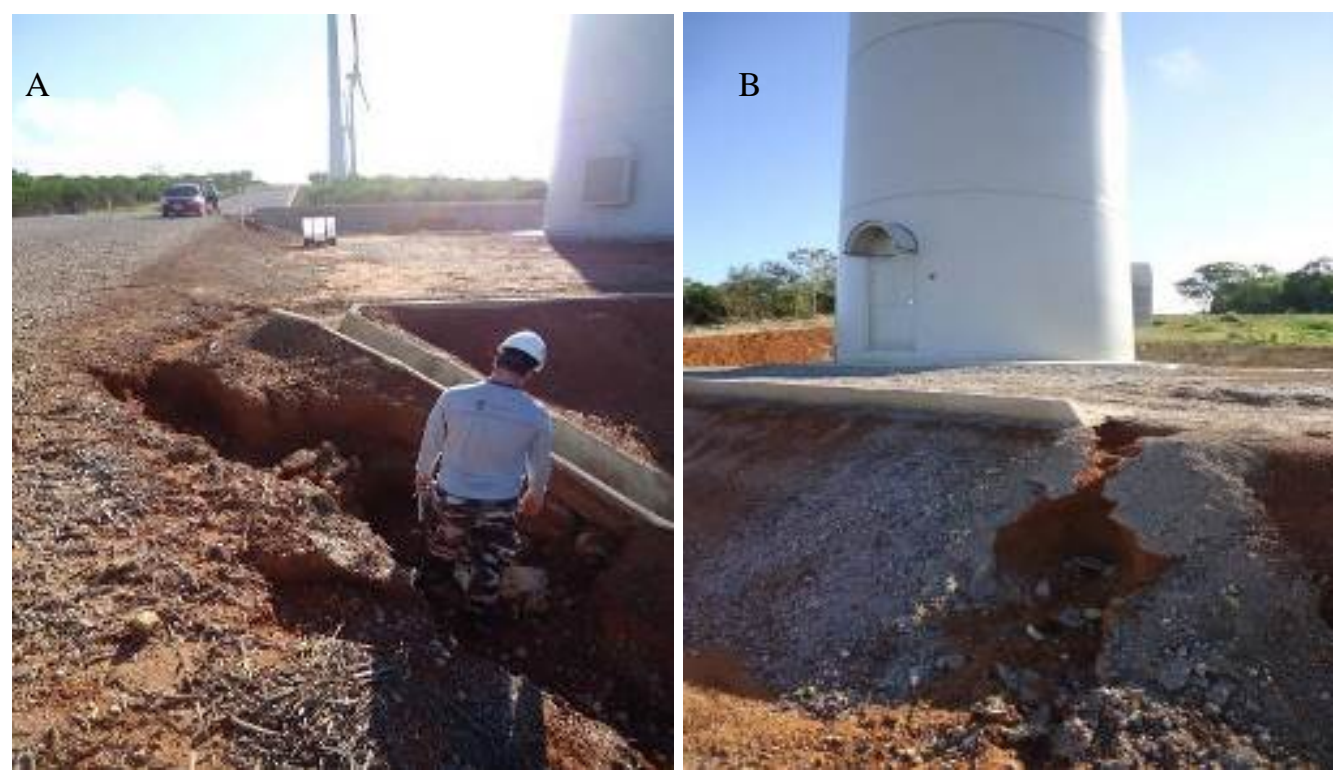

Figura 02 - Principais processos erosivos ocorrentes em parques eólicos na região Agreste do RN, causado por forte escoamento laminar, acentuados pela variação topográfica (A) e pela diferença de gradiente no talude (B). Fonte. O autor.

A erosão verificada acima está presente em grande parte dos locais com grande diferença topográfica, mas associado a esse fator verifica-se, também, que a forma dos acessos e a estabilização dos taludes são fatores que contribuem para o aumento da velocidade do fluxo d'água no período chuvoso, pois se os acessos não apresentam boa compactação e abaulamento de suas vias, os taludes internos dos parques não comportam a retirada do sedimento, o que acarreta na formação dos sulcos e ravinas mostradas.

Para a referida área, a recomendação para a conservação do solo e, consequentemente, para atenuar os processos erosivos, são deque haja a introdução de vegetação nativa, com maior resistência a longos períodos de estiagem, característicos à região. Em processos erosivos mais avançados, a reposição do solo e o enrocamento a partir de pequenos blocos de matacão são alternativas viáveis para esses casos.

Ainda para a referida área, o uso condicional de britas nas vias de acesso ajudam no aumento do atrito entre os veículos que circulam, fazendo com que o transporte eólico não se torne um fator preponderante no que tange a atuação da erosão local.

\section{Monitoramento e Processos erosivos do complexo eólico no litoral Cearense}

A área correspondente ao Litoral Cearense tem como principal agente intempérico os ventos, que acarretam processos erosivos de natureza eólica. Associado a atuação deste fator natural, verifica-se que a área do complexo eólico possui uma variação topográfica expressiva 
associada a significativas parcelas de solos expostos. Os principais resultados decorrentes da erosão eólica verificados em nível local dizem respeito a mobilização sedimentar arenosa que acarreta a migração de sedimentos sobrepondo as áreas das plataformas dos aerogeradores, assim como das vias de acesso aos aerogeradores (Figura 03).
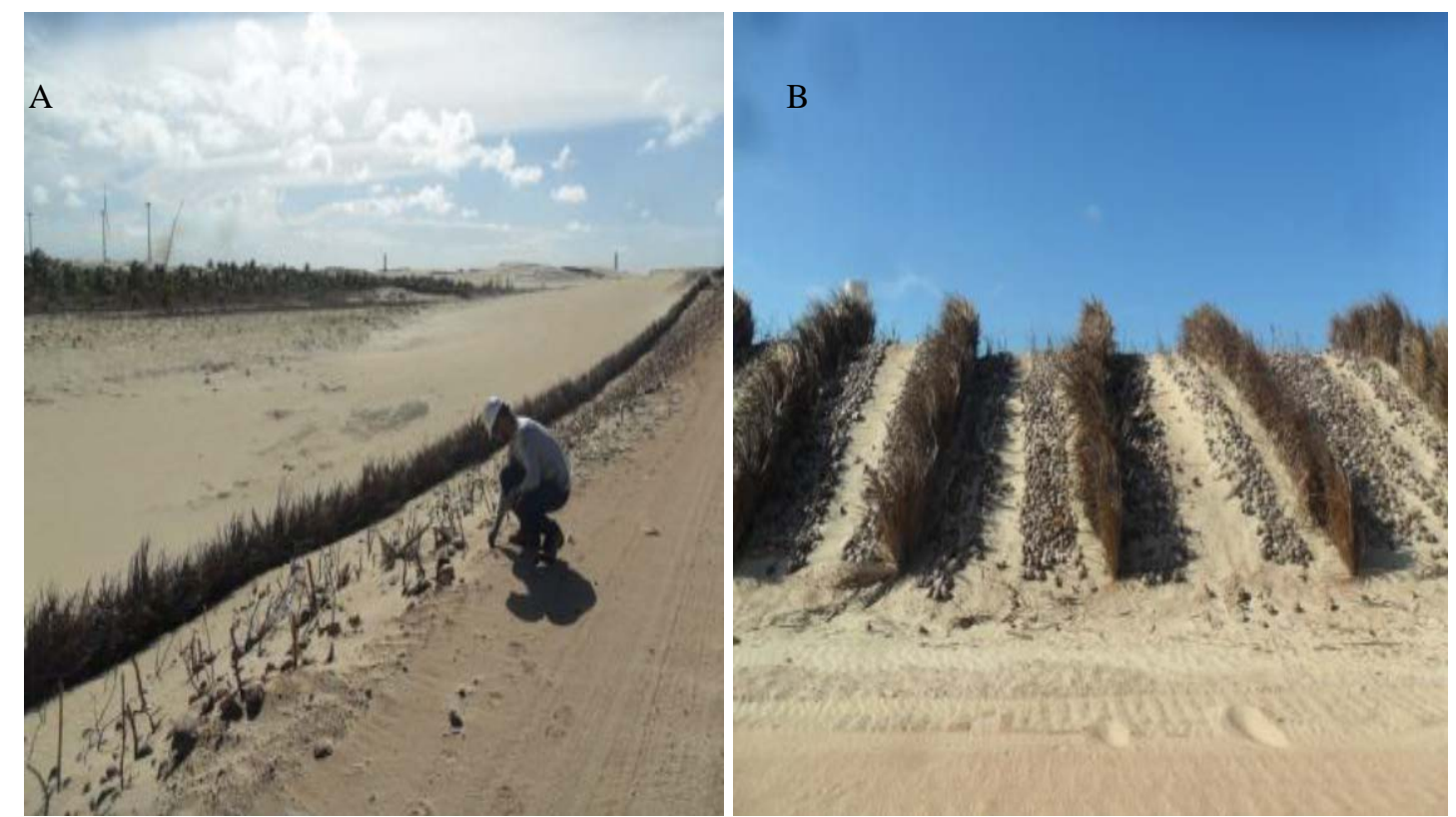

Figura 03 - Principais processos erosivos ocorrentes em parques eólicos na região litorânea, decorrente do fluxo sedimentar eólico das dunas (A) e a atenuado por técnicas de atenuação dos processos erosivos através de palhas e buchas de coco (B). Fonte. O autor.

A erosão apontada acima está presente em grande parte dos locais do complexo eólico em questão, devido à diferença topográfica e, as significativas parcelas de solo desnudo, mas associado a esse fator verifica-se, também, que a forma dos acessos e a estabilização dos taludes são fatores que contribuem para o incremento sedimentar, pois se os acessos não apresentam um bom isolamento e abaulamento de suas vias, os taludes internos dos parques eólicos não comportam o suprimento excessivo de sedimentos que ora se depositam, os quais são provenientes das áreas de dunas adjacentes que sofreram com a erosão eólica.

Para esta área, a recomendação para a conservação do solo e, consequentemente, para atenuar os processos erosivos, são aqueles já apresentados nas imagens acima: o uso da palha e bucha do coco, como mecanismos de redirecionamento das partículas transportadas pelo vento. Além desse fator de contenção, recomenda-se para tais áreas a introdução de vegetação nativa, sobretudo as que apresentam melhor adaptação à ambientes arenosos. Em processos erosivos mais avançados, o uso intensivo da contenção com palhas e bucha de coco atenua momentaneamente o transporte dos sedimentos. Para mitigação de quaisquer processos erosivos avançados, a única 
solução observada para tal localidade é reposição do material transportado por meio de veículos adaptados (tratores, caçambas, patrol, etc).

\section{CONSIDERAÇÕES FINAIS}

Os processos erosivos conforme mencionados ao longo deste artigo ocorrem em caráter natural, contudo, por vezes, é acentuado pelo exercício das atividades humanas que promovem alterações ambientais com vistas a atender as suas demandas construtivas e, de respectivo uso e ocupação do solo.

No âmbito dos aspectos construtivos dos parques eólicos das regiões agreste e litoral dos Estados do Rio Grande do Norte e Ceará, respectivamente, as demandas de implantação de parques eólicos requerem o uso do solo como fator condicionador para implantação das referidas estruturas, trazendo consigo alterações na configuração física do solo, acarretando, principalmente, a ocorrência e/ou acentuação de processos erosivos em áreas de talude com maior declividade.

A consecução de planos de controle e monitoramento de processos erosivos se oportuna como algo de grande relevância em termos de colaboração com a manutenção do equilíbrio ambiental e físico-territorial. Na execução dos referidos planos, ressalta-se como adoção de medidas mitigadoras que contemplem a conservação dos solos, o uso de vegetação nativa nas áreas apontadas como frágeis, de forma a diminuir introdução de espécies com maior dependência de água.

Ainda no contexto apresentado, sugere-se o acompanhamento sistêmico em todas as áreas mencionadas acima, haja vista que estas sofrem constantes alterações no regime hídrico causado pela escassez de chuvas da região, assim como sofrem com a grande dinamicidade decorrente da atuação eólica vigente nas regiões.

Outrossim, a interrelação entre as atividades antropogênicas com o desenvolvimento da matriz energética renovável deve ser encarada como uma demanda necessária e inerente ao crescimento de diversos setores produtivos. Mas, entretanto, como demonstrado no arcabouço desse estudo, as técnicas de conservação do solo nessas áreas, independente da região geográfica que ocupam, devem ser oportunamente aplicadas em todas as fases construtivas, em especial na fase de implantação, onde incidem os maiores processos erosivos, cuja antecipação a estes poderá ser evitado com as técnicas necessárias.

\section{REFERÊNCIAS}


BERTONI, J. Conservação do solo. 5. ed. São Paulo: Ícone, 2005.

CASSETI, Valter. Ambiente e apropriação do relevo. São Paulo: Contexto, 1996.

GUERRA, A. J. T.; Silva, A. S.; Machado, R. G. (Org.). Erosão e conservação dos solos: conceitos, temas e aplicações. Rio de Janeiro: Edgard Blucher, 2007.

SILVA, Anieres Barbosa da; GOMES Rita de Cássia da Conceição; SILVA Valdenildo Pedro da. Meio ambiente e qualidade de vida: Apontamentos iniciais sobre Percepções e práticas nas áreas produtoras de petróleo no Rio Grande do Norte. Conferência Internacional da Terra, João Pessoa - PB, 2008.

WHITE, Robert E. Princípios e práticas da ciência do solo: o solo como um recurso natural. 4. ed. São Paulo: Andrei, 2009.

\section{AGRADECIMENTOS}

Agradecimento especial à CRN-Bio Consultorias Integradas, pelas informações e dados confiados à pesquisa.

Recebido em: 14/08/2016

Aceito para publicação em: 01/10/2016 